Check for updates

Cite this: RSC Adv., 2018, 8, 37700

\title{
Proton conductive ionic liquid crystalline poly(ethyleneimine) polymers functionalized with oxadiazole $\uparrow$
}

\author{
Alberto Concellón, (D) † Silvia Hernández-Ainsa, (D) bc Joaquín Barberá, (D) ${ }^{a}$ \\ Pilar Romero, (iD ${ }^{a}$ José Luis Serrano (ID ${ }^{b}$ and Mercedes Marcos (iD)*a
}

\begin{abstract}
Two novel series of ionic liquid crystal polymers that display proton conductive properties are presented here. These materials are based on linear (l-PEI) or branched (b-PEI) poly(ethyleneimine) functionalized with unsymmetrical oxadiazole carboxylic acids derived from 1,3,4-oxadiazole (1,3,4-OXA or 1,2,4-oxadiazole $\left(1,2,4-\mathrm{OXA}_{m}\right)$. The subscript " $m$ " indicates the length of the spacer between the rigid moiety and the carboxyl group, namely $m=4$ and 10 . The occurrence of proton transfer from the carboxylic acid to the amine groups was confirmed by FTIR and NMR measurements. The liquid crystalline properties were investigated by differential scanning calorimetry (DSC), polarizing optical microscopy (POM), and X-ray diffraction (XRD). All ionic complexes displayed enantiotropic smectic A mesophases and in the case of the l-PEI derivatives a nematic phase was also observed at high temperatures. All investigated derivatives presented good proton conductivity values as determined by electrochemical impedance spectroscopy (EIS). Therefore, these ionic LC hyperbranched polymers represent an effective approach for the preparation of proton-transporting polymeric materials with potential applications in electrochemical devices.
\end{abstract}

Received 5th October 2018

Accepted 26th October 2018

DOI: $10.1039 / \mathrm{c} 8 \mathrm{ra0} 8253 \mathrm{~g}$

rsc.li/rsc-advances poly(propyleneimine) (PPI), poly(amidoamine) (PAMAM), or poly(ethyleneimine) (PEI) complexed with different carboxylic acids by a proton transfer reaction between the carboxylic acids and the basic amine groups. ${ }^{13-18}$

In this regard, our research group has a large record on studying the LC properties of ionic dendrimers. We reported several examples of ionic LC dendrimers based on different generations of PAMAM and PPI that exhibited different properties depending on the characteristics of the attached carboxylic acids. Specifically, the functionalization with aliphatic carboxylic acids ${ }^{\mathbf{1 9 - 2 2}}$ or with an azobenzene containing carboxylic acid produced high and stable photoinduced birefringence. $^{23}$ Other derivatives bearing 1,3,4-oxadiazole or 1,2,4oxadiazole rings ${ }^{24}$ exhibited good luminescent properties, whereas the introduction of carbazole rings ${ }^{25}$ resulted into good luminescent and electrochemical properties. The well-defined segregation in layers is responsible for the smectic LC behavior exhibited by most of these dendrimers.

We recently developed a new versatile approach for the preparation of proton-conductive materials by using ionic LC dendrimers synthesized from PAMAM dendrimers surrounded by carboxylic acid dendrons bi-functionalized with a promesogenic unit (cholesteryl hemisuccinate) and coumarin moieties. ${ }^{26}$ All the materials showed good proton conductive properties as the LC arrangement resulted in ionic nanosegregated areas (formed by the ion pairs) that favoured proton conduction.

Aiming to expand the library of ionic LC dendritic materials showing proton conductive properties, we present here two 
novel series of ionic LC polymers. These are derived from linear ( $\boldsymbol{l}$-PEI) or branched (b-PEI) poly(ethyleneimine) containing 1,3,4-oxadiazole $\left(\mathbf{1}, \mathbf{3}, \mathbf{4}-\mathbf{O X} \mathbf{A}_{m}\right)$ or 1,2,4-oxadiazole $\left(\mathbf{1}, \mathbf{2}, \mathbf{4}-\mathbf{O X A} \mathbf{X}_{m}\right)$ carboxylic acids (the subscript " $m$ " indicates the length of the spacer between the rigid moiety and the carboxyl group, namely $m=4$ or 10 ), with unsymmetrical substitutions (Scheme 1 ). In this work $\boldsymbol{b}$-PEI was chosen because hyperbranched polymers are likely to have more practical applications than dendrimers as they are prepared very easily (by a one-pot synthesis), while retaining some of the structural features and properties of dendrimers (yielded through tedious and costly multi-step reactions). ${ }^{27}$ Herein, we report the synthesis, characterization and mesomorphic properties of these ionic LC polymers (linear and branched) with the objective of assessing their possible use as new proton conductive materials for electrochemical devices.

\section{Experimental section}

\section{Synthesis and nomenclature of the oxadiazole acids}

Two oxadiazole isomers (1,3,4- and 1,2,4-) were used to prepare the acids. They are denoted as 1,3,4-OXA $\mathbf{A}_{m}$ and 1,2,4-OXA $\mathbf{A}_{m}$. The subscript " $m$ " indicates the length of the spacer between the rigid moiety and the carboxyl group, namely $m=4$ and 10 . Scheme 1 shows the structure of the different acids. The preparation of the acids was reported previously. ${ }^{24}$

\section{Synthesis and nomenclature of the ionic polymers}

Ionic polymers were synthesized as schematically represented in Scheme 1, following a previously described method. ${ }^{19} n$ equiv. of the corresponding oxadiazole acid were dissolved in anhydrous tetrahydrofuran (THF) and were added to a solution
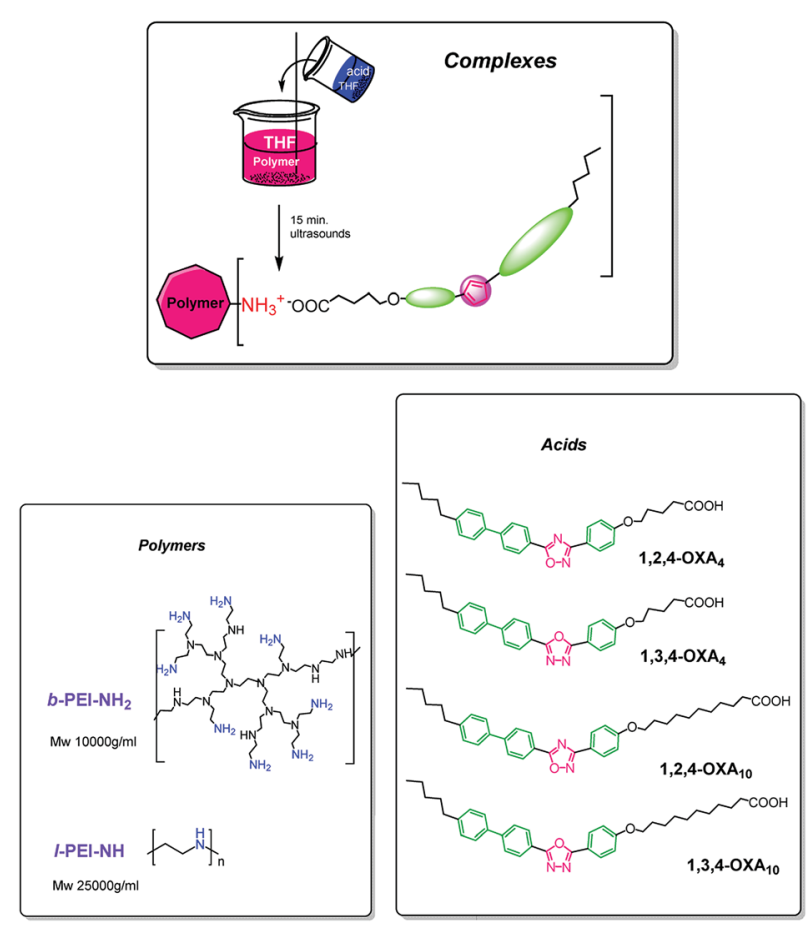

Scheme 1 Schematic representation of the synthetic route to give the ionic complexes and their chemical structure. of 1 equiv. of the corresponding PEI polymer in anhydrous THF. The mixture was sonicated for 15 minutes, and then it was slowly evaporated at room temperature and dried under vacuum for ca. $12 \mathrm{~h}$ at $40{ }^{\circ} \mathrm{C}$ until the weight remains constant. These compounds are named $\boldsymbol{b}$-PEI-(1,3,4-OXA $)_{n}, \boldsymbol{b}$-PEI-(1,2,4$\left.\mathrm{OXA}_{4}\right)_{n}, b$-PEI-(1,3,4-OXA $\left.{ }_{10}\right)_{n}, b$-PEI-(1,2,4-OXA 10$)_{n}, l$-PEI-(1,3,4$\left.\mathrm{OXA}_{4}\right)_{n}$ and $l$-PEI- $\left(1,2,4-\mathrm{OXA}_{4}\right)_{n}$.

\section{Results and discussion}

\section{Characterization of the ionic polymers}

FTIR characterization. The formation of the ionic complexes was confirmed by FTIR spectroscopy (Table S1 $\dagger$ ). The band at $1707-1699 \mathrm{~cm}^{-1}$ of the carbonyl groups of 1,3,4-OXA $m$ acids was replaced by a new band corresponding to the asymmetric stretching band at $1556 \mathrm{~cm}^{-1}$ of the carboxylate groups in the ionic $\boldsymbol{b}$-PEI dendritic polymer. The same behavior was also observed for the dendrimers of the series 1,2,4-OXA $\mathbf{A}_{m}$, with a displacement of the band of the carbonyl group in the 1,2,4OXA $_{m}$ acids from $1707 \mathrm{~cm}^{-1}$ to $1559 \mathrm{~cm}^{-1}$ or $1589 \mathrm{~cm}^{-1}$, upon formation of the carboxylate group in the ionic $\boldsymbol{b}$-PEI dendritic polymer or $\boldsymbol{l}$-PEI linear polymer respectively.

NMR experiments. The formation of the ionic complexes was also confirmed by NMR studies either in solution (onedimensional ${ }^{1} \mathrm{H}$ and ${ }^{13} \mathrm{C}$ NMR spectroscopy as well as twodimensional ${ }^{1} \mathrm{H}-{ }^{1} \mathrm{H}$ COSY, ${ }^{1} \mathrm{H}-{ }^{13} \mathrm{C}$ HSQC, and ${ }^{1} \mathrm{H}-{ }^{13} \mathrm{C}$ HMBC experiments) or by solid-state cross-polarization magic angle spinning (CPMAS) ${ }^{13} \mathrm{C}$ NMR spectroscopy, depending on the solubility of the compounds. The shift variations of the signals of the main protons and carbons involved in ionic complexes formation are gathered in Table S2 and S3 of the ESI. $\dagger$

Selected examples of NMR spectra of the ionic complexes derived from 1,2,4-OXA 4 are shown in Fig. 1 and 2. The broad

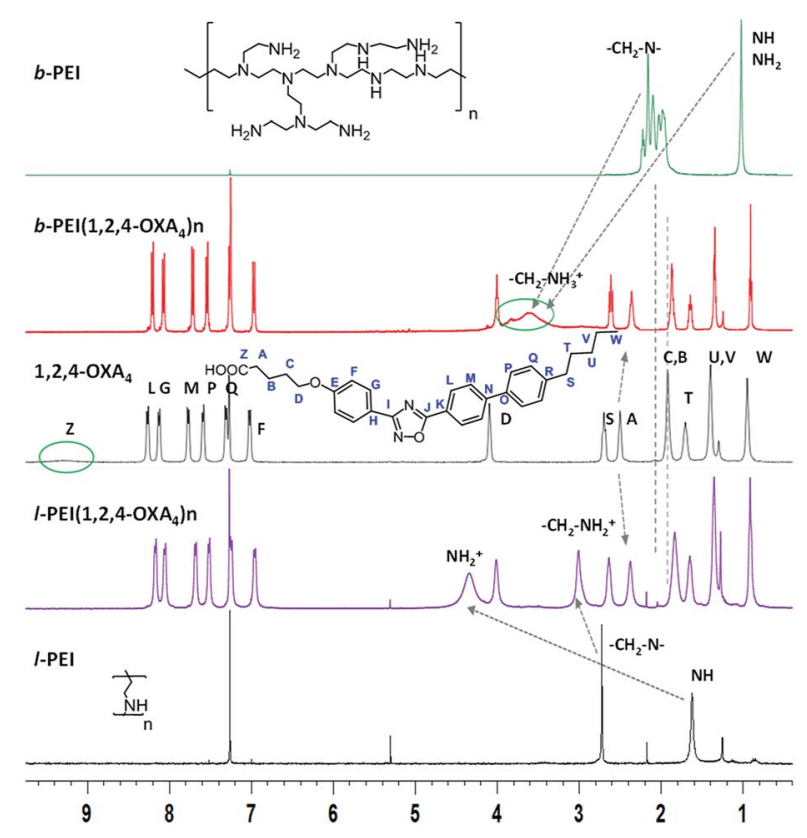

Fig. $1{ }^{1} \mathrm{H}$ NMR spectra in $\mathrm{CDCl}_{3}$ of ionic complexes $b$-PEI(1,2,4-OXA $)_{n}$ and $l$-PEI $\left(1,2,4-\mathrm{OXA}_{4}\right)_{n}$ as well as of the $\left(1,2,4-\mathrm{OXA}_{4}\right)$ acid and the hyperbranched $(b-\mathrm{PEI})$ and linear (l-PEI) poly(ethyleneimine) polymers. 


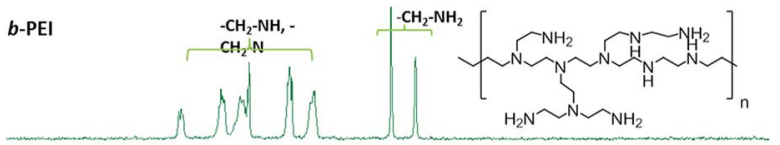

$b$-PEI(1,2,4-OXA 4$) n$
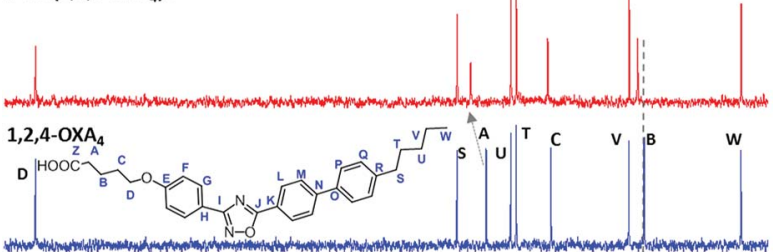

I-PEI(1,2,4-OXA 4$)$ n

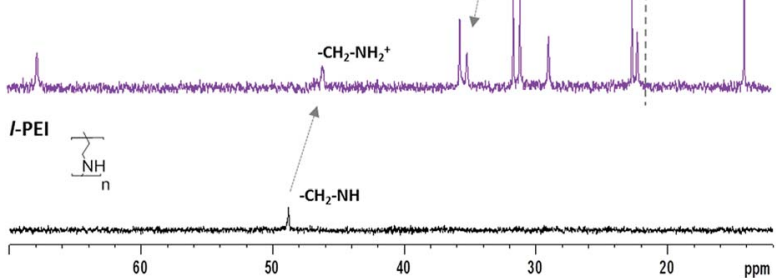

Fig. $2{ }^{13} \mathrm{C}$ NMR spectra in $\mathrm{CDCl}_{3}$ of complexes $b$-PEI(1,2,4-OXA 4$)_{n}$ and $l$-PEI $\left(1,2,4-\mathrm{OXA}_{4}\right)_{n}$ as well as of the $\left(1,2,4-\mathrm{OXA}_{4}\right)$ acid and the hyperbranched (b-PEI) and linear (l-PEI) poly(ethyleneimine) polymers.

signal at 9.20-9.60 ppm corresponding to the carboxylic acid proton $\left(\mathrm{H}_{\mathrm{Z}}\right)$ of the oxadiazole derivative disappeared in the ${ }^{1} \mathrm{H}$ NMR spectra of the complexes. In addition, the ${ }^{13} \mathrm{C}$ signal of the carboxylic group was slightly shifted upfield in the spectra of the ionic complexes. A shifting of $-0.06 \mathrm{ppm}$ was also observed for the methylene protons $\left(\mathrm{H}_{\mathrm{A}}\right)$ in alpha position to the carboxylic group of the oxadiazole derivatives. In the same way, the ionic complexes formation was also corroborated by the displacement of the methylene $\mathrm{C}_{\mathrm{A}}$ carbon signal from 33.6 to 34.6$35.1 \mathrm{ppm}$.

Moreover, protons of the terminal amine groups and methylene protons of the dendritic part underwent a considerable deshielding in the ${ }^{1} \mathrm{H}$ NMR spectra. The ${ }^{13} \mathrm{C}$ signals of these methylene groups also shifted from 49.1 to $46.1 \mathrm{ppm}$ for $\boldsymbol{l}$-PEI complex. In the case of $\boldsymbol{b}$-PEI $\left(\mathbf{1}, \mathbf{2}, \mathbf{4}-\mathbf{O X A}_{\mathbf{4}}\right)_{\boldsymbol{n}}$ complex, the shifts of these methylene groups could not be determined due to its low solubility in $\mathrm{CDCl}_{3}$, but it was confirmed by HSQC experiments in $\mathrm{DMSO}_{6} \mathrm{~d}_{6}$ (see Fig. $\mathrm{S} 1 \dagger$ ).

Furthermore, the ${ }^{1} \mathrm{H}-{ }^{1} \mathrm{H}$ NOESY experiment showed crosspeaks between the methylene groups in alpha $\left(\mathrm{C}_{\mathrm{A}}\right)$ or beta $\left(\mathrm{C}_{\mathrm{B}}\right)$ position to the carboxylate and the PEI-amine protons, confirming the formation of the ion pairs (see Fig. S2 $\dagger$ ).

${ }^{13} \mathrm{C}$ CPMAS experiments were carried out in the case of insoluble complexes. In these spectra, the branched PEI ( $\boldsymbol{b}$-PEI) can be observed forming part of the ionic complex. The signal of the carboxylic acid is spread out in the frequency domain and the packing of oxadiazole core differs with regard to the packing of the initial acids (Fig. 3).

\section{Thermal stability of the polymers}

The thermal stability of the ionic dendrimers was studied by thermogravimetric analysis (TGA). All the samples showed good thermal stability and in all cases the 5\% weight loss (a)

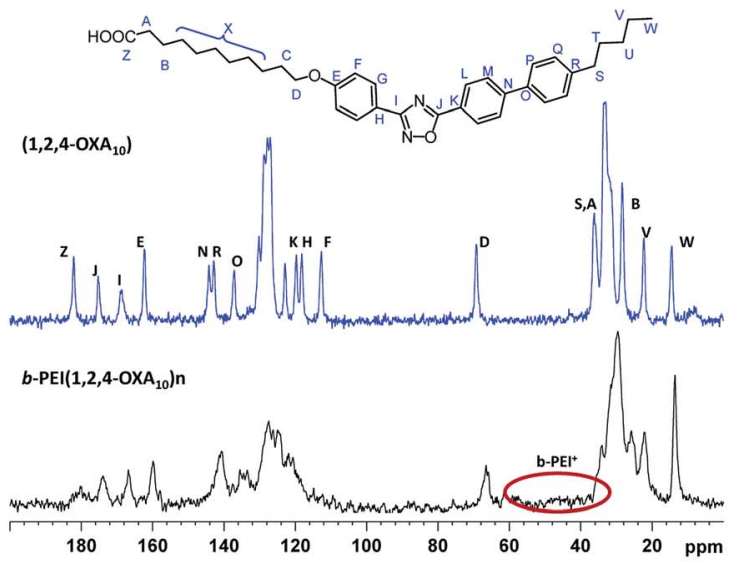

(b)

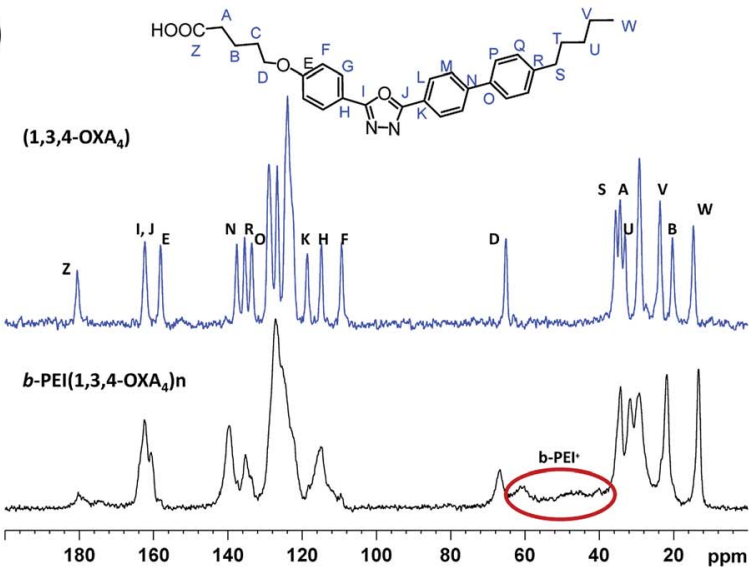

Fig. $3{ }^{13} \mathrm{C}$ CPMAS spectra of $b$-PEI complexes (bottom) and their corresponding acids (top): (a) $b$-PEI(1,2,4-OXA10) $n$ and (b) $b$-PEI(1,3,4OXA4) $_{n}$.

temperature $\left(T_{5 \%}\right)$ was detected at temperatures above the isotropization point (Table S4, Fig. S9a†).

\section{Liquid crystal properties}

The mesomorphic behavior of the compounds was analyzed by POM and DSC. Three cycles were carried out in DSC experiments and data were taken from the second cycle. In some cases, the isotropization temperatures were taken from POM observations because no transition peaks were detected in the DSC curves (Table 1). The nature of the mesophase was also confirmed by X-ray diffraction (XRD).

Liquid crystal properties of the acids. The type of oxadiazole moiety plays a important role in the liquid crystal behavior. 1,2,4-OXA $\boldsymbol{m}$ carboxylic acids $(m=4,10)$ exhibited two different enantiotropic mesophases: a smectic A (SmA) at low temperatures, and a nematic (N) at high temperatures (Fig. $4 \mathrm{a}$ and $\mathrm{b}$ ).

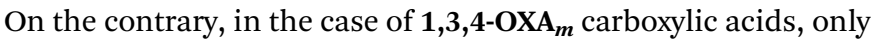
1,3,4-OXA 4 exhibited a N monotropic mesophase; whereas 1,3,4$\mathbf{O X A}_{10}$ did not show liquid crystal properties (Fig. 4c and d).

Liquid crystal properties of the ionic polymers. All polymers presented SmA mesomorphism as revealed the textures observed by POM, and were subsequently confirmed by XRD. Linear polymers $\boldsymbol{l}$-PEI-(1,2,4-OXA $)_{n}$ and $\boldsymbol{l}$-PEI-(1,3,4-OXA $)_{n}$ also 
Table 1 Temperatures and enthalpies of the phase transitions of the acids and ionic polymers

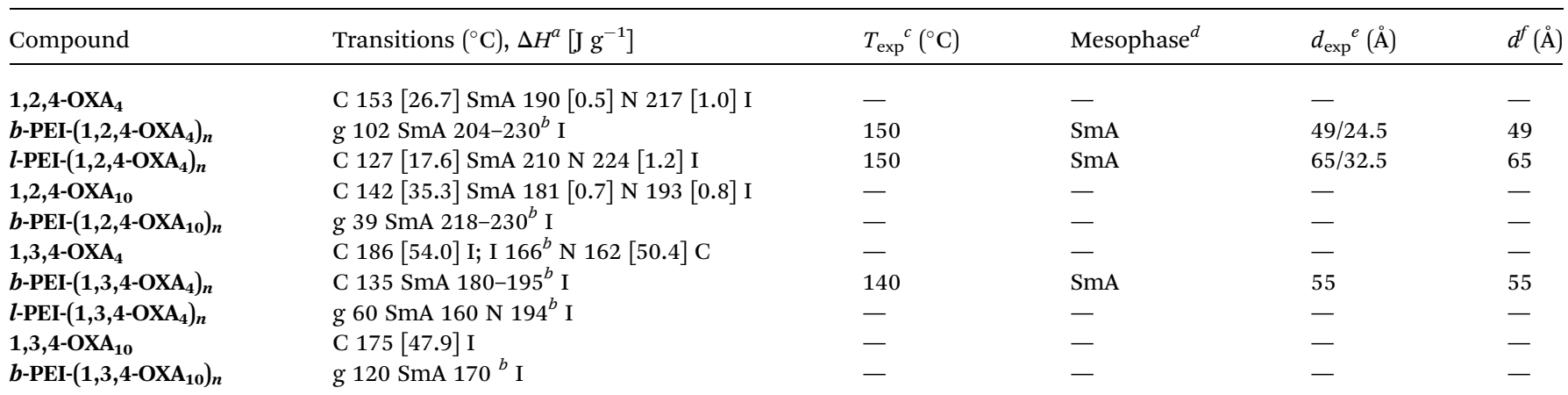

${ }^{a}$ Data from the second scan and taken at the maximum of the peak. $\mathrm{C}=$ crystal, $\mathrm{g}=$ mesomorphic glass, $\mathrm{N}=$ nematic mesophase, $\mathrm{I}=$ isotropic liquid. ${ }^{b}$ Data taken from POM. ${ }^{c}$ Temperature of the XRD experiment. ${ }^{d}$ Mesophase exhibited by the compounds at the given temperature. ${ }^{e}$ Measured spacings. ${ }^{f} d=$ layer spacing $(\AA)$ of the smectic phase.

exhibited a $\mathrm{N}$ mesophase at high temperature (Table 1). Representative textures of the LC phases are shown in Fig. 5 (and Fig. S3-S8†). The polymer scaffold plays an important role in liquid crystal properties of the ionic complexes as can be observed in Table 1. Compounds derived from $\boldsymbol{b}$-PEI polymer exhibited only a SmA mesophase, whereas compounds derived from $\boldsymbol{l}$-PEI polymer exhibit two different mesophases (SmA and N). See Fig. S9† for a representative example of a DSC curve.

The type of oxadiazole isomer also influences the liquid crystal properties due to the different exocyclic bond angles and the different polarity of the 1,3,4-oxadiazole or 1,2,4-oxadiazole central heterocyclic rings. For instance, LC transition temperatures are strongly affected by the oxadiazole isomers. The compounds derived from 1,2,4-oxadiazole exhibited lower melting points but higher isotropization temperatures compared to those displayed by the 1,3,4-oxadiazole homologues. Consequently, 1,2,4-oxadiazole produced broader mesomorphic temperature ranges (see Table 1).

$\mathrm{X}$-ray studies of the mesophases. X-ray diffraction measurements were carried out at variable temperatures on compounds
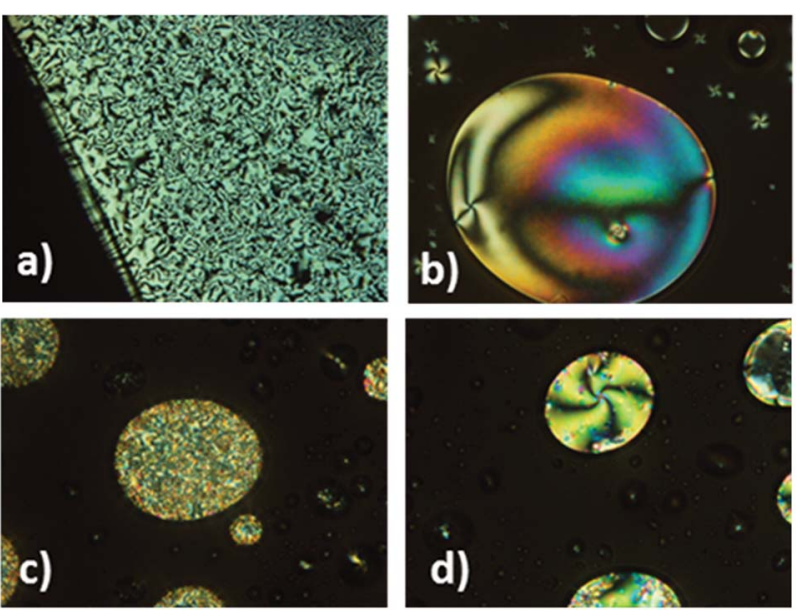

Fig. 4 POM textures of (a) $1,2,4-\mathrm{OXA}_{4}$ (taken at $215^{\circ} \mathrm{C}$ in the $1^{\text {st }}$ cooling), (b) $1,2,4-O X A_{10}$ (taken at $191^{\circ} \mathrm{C}$, in the $1^{\text {st }}$ cooling), (c) 1,3,4$\mathrm{OXA}_{4}$ (taken at $160{ }^{\circ} \mathrm{C}$ in the $4^{\text {th }}$ cooling), and (d) $1,3,4-\mathrm{OXA}_{4}$ (nematic droplets taken at $160^{\circ} \mathrm{C}$ in the $1^{\text {st }}$ cooling).
$b$-PEI-(1,2,4-OXA $)_{n}, l$-PEI-(1,2,4-OXA $)_{n}$ and $b$-PEI-(1,3,4-OXA $)_{n}$, using a powder X-ray apparatus equipped with a heating plate. In all cases the obtained patterns were consistent with a smectic arrangement in the investigated thermal range (up to $150{ }^{\circ} \mathrm{C}$ ). High temperatures led to thermal decomposition of the samples during the exposure times, and therefore the nematic mesophase of $\boldsymbol{l}$-PEI-(1,2,4-OXA $)_{\boldsymbol{n}}$ could not be investigated. The $\mathrm{X}$-ray patterns contained a set of one or two sharp maxima in the low-angle region corresponding to the first and second order reflections of the layers, as expected for a lamellar arrangement of the molecules (Fig. S10†). The interlayer periodicity or layer thickness $(d)$ can be deduced from the spacing of these reflections, and the obtained values are gathered in Table 1. In the high-angle region the patterns contained only a broad and diffuse halo, characteristic of the liquid-like arrangement of the molecules within each layer. These features are consistent with the smectic A nature of the mesophase assigned by POM.
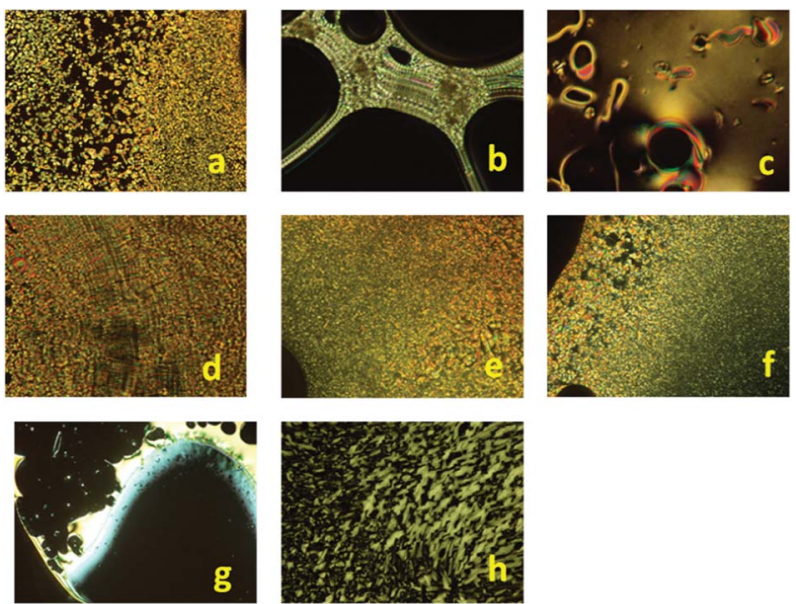

Fig. 5 POM textures of: (a) $b$-PEI- $\left(1,2,4-\mathrm{OXA}_{4}\right)_{n}$ (taken at $179^{\circ} \mathrm{C}$ in the $2^{\text {nd }}$ cooling), (b) $l$-PEI- $\left(1,2,4-\mathrm{OXA}_{4}\right)_{n}$ (taken at $152^{\circ} \mathrm{C}$ in the $1^{\text {st }}$ heating), (c) l-PEI-(1,2,4-OXA $)_{n}$ (taken at $222{ }^{\circ} \mathrm{C}$, in the $1^{\text {st }}$ cooling), (d) $b$-PEI$\left(1,2,4-\mathrm{OXA}_{10}\right)_{n}$ (taken at $229^{\circ} \mathrm{C}$ in the $1^{\text {st }}$ heating), (e) $b$-PEI- $(1,3,4-$ $\left.\mathrm{OXA}_{4}\right)_{n}$ (taken at $170{ }^{\circ} \mathrm{C}$ in the $2^{\text {nd }}$ cooling), (f) $b$-PEI- $\left(1,3,4-\mathrm{OXA}_{10}\right)_{n}$ (taken at $155^{\circ} \mathrm{C}$ in the $2^{\text {nd }}$ cooling), (g) l-PEI- $\left(1,3,4-\mathrm{OXA}_{4}\right)_{n}$ (taken at $163{ }^{\circ} \mathrm{C}$, in the $1^{\text {st }}$ cooling), (h) l-PEI- $\left(1,3,4-\mathrm{OXA}_{4}\right)_{n}$ (taken at $105^{\circ} \mathrm{C}$ in the 2 nd heating). 
The layer spacing values $(d)$ shown in Table 1 depend on the compound. The layer thickness value displayed by the branched b-PEI-(1,2,4-OXA $)_{\boldsymbol{n}}$ derivative is contracted compared to homologous lineal derivative $\left.(\boldsymbol{l} \text {-PEI-(1,2,4-OXA })_{\mathbf{n}}\right)$. On the other hand for compound $\boldsymbol{b}$-PEI-(1,3,4-OXA $)_{\mathbf{n}}$, containing the other regioisomeric oxadiazole ring, the layer spacing is intermediate between those of $\boldsymbol{b}$-PEI-(1,2,4-OXA $)_{n}$ and $\boldsymbol{l}$-PEI-(1,2,4-OXA $)_{n}$. The experimentally-measured layer thickness for the mesophase of these compounds is consistent with a molecular arrangement in which the poly(ethyleneimine) part of the molecule is located in the inner part of each layer and the mesogenic units statistically extend upwards and downwards to both layer boundaries. This structural model has been previously described by us for similar ionic and non-ionic mesogenic dendrimers. ${ }^{24}$

The variations in the layer thickness as a function of each particular compound are probably due to the high conformational freedom of the poly(ethyleneimine) polymer. As a consequence, the thickness of the central slab of the layer occupied by the poly(ethyleneimine) moiety can change to a great extent and this produces an important variation in the total layer thickness. Moreover, there can be some interpenetration between neighbouring layers through interdigitation of the mesogenic units. This phenomenon seems to be more favored in the case of the $\boldsymbol{b}$-PEI derivatives, as can be deduced from their smaller layer thickness compared to $\boldsymbol{l}$-PEI-(1,2,4$\left.\mathbf{O X A}_{4}\right)_{n}$, probably as a consequence of the different conformational behavior of each type of poly(ethyleneimine) unit. In addition to this, the nature of the oxadiazole exerts an influence on the layer spacing with $\boldsymbol{b}$-PEI-(1,3,4-OXA $)_{\mathbf{n}}$ showing larger value than $\boldsymbol{b}$-PEI-(1,2,4-OXA $)_{\boldsymbol{n}}$. This phenomenon is probably related to a larger degree of interdigitation for the mesogenic unit based on 1,2,4-oxadiazole.

It is interesting to note that, while the second order layer reflection is absent for $\boldsymbol{b}$-PEI-(1,3,4-OXA $)_{n}$, this reflection is clearly visible for $\boldsymbol{b}$-PEI-(1,2,4-OXA $)_{n}$ and $\boldsymbol{l}$-PEI-(1,2,4-OXA $)_{n}$. Moreover its intensity is higher than usual, and for compound $\boldsymbol{b}$-PEI-(1,2,4-OXA $)_{n}$ it is even stronger than the first order reflection. This unusual feature found for the two polymers containing the mesogenic unit derived form 1,2,4-oxadiazole must arise from the presence of a period $d / 2$ in the electrondensity wave in the direction perpendicular to the layers. Similar behavior has been previously reported for some sidechain liquid-crystalline polymers and it is explained by the confinement of the polymeric backbones in a thin sublayer, so that the polymeric backbones produce an electron-density maximum comparable to that of the mesogenic cores. ${ }^{28,29}$

\section{Proton conductive properties}

The proton conductivity was measured using electrochemical impedance spectroscopy (EIS) in samples consisting of films sandwiched between ITO-coated electrodes. The typical EIS response (Nyquist plots) consisted of a suppressed semicircle in the high-frequency region and an incline straight line in the low-frequency range. Since diffusible ions apart from protons did not exist in the compounds, the observed EIS responses were ascribed to proton conduction, which was calculated from the EIS responses and the cell constant (see Experimental Section in the ESI $\dagger$ ).

The proton conductivities of some selected complexes were measured to investigate the effect of the dendrimer core, oxadiazole regioisomer type and length of the spacer on this property. Namely, the proton conductivities of $\boldsymbol{b}$-PEI-(1,2,4-OXA $)_{n}, \boldsymbol{b}$ PEI-(1,2,4-OXA 10$)_{n}, \quad b$-PEI-(1,3,4-OXA $\left.)_{10}\right)_{n}$ and $l$-PEI-(1,3,4-OXA 4$)$ were measured as a function of the temperature (Fig. 6). For all the ionic compounds, the conductivities increased as the temperature increased from $30{ }^{\circ} \mathrm{C}$ to $225{ }^{\circ} \mathrm{C}$ (from $303 \mathrm{~K}$ to 498 $\mathrm{K})$. A plateau was observed once the isotropic state was reached.

At low temperatures, conductivities of $\boldsymbol{b}$-PEI-(1,2,4-OXA ) $_{\boldsymbol{n}}$ (see red data in Fig. 6) increased respect to those measured in $\boldsymbol{b}$-PEI$\left(\mathbf{1}, \mathbf{2}, \mathbf{4}-\mathbf{O X A}_{10}\right)_{n}$ (see light blue data in Fig. 6), indicating that the longer alkyl spacer reduces conductivity. For instance, conductivity values of $\boldsymbol{b}$-PEI-(1,2,4-OXA $\left.\mathbf{1}_{\mathbf{1 0}}\right)_{\boldsymbol{n}}$ and $\boldsymbol{b}$-PEI-(1,2,4-OXA $)_{\boldsymbol{n}}$ at $50{ }^{\circ} \mathrm{C}(323 \mathrm{~K})$ were $3 \times 10^{-10}$ and $1 \times 10^{-9} \mathrm{~S} \mathrm{~cm}^{-1}$, respectively. This enhanced conductivity in $\boldsymbol{b}$-PEI-(1,2,4-OXA $\left.\mathbf{1 0}_{\boldsymbol{n}}\right)_{\boldsymbol{n}}$ may be related to the more efficient molecular packing produced by this derivative in the smectic mesophase. It has been previously described that oxadiazole moieties with longer spacers favor a more efficient interaction between neighboring oxadiazoles, while shorter spacers preclude such interactions. ${ }^{31}$ Thus, the mean effective hopping distances in $\boldsymbol{b}$-PEI-(1,2,4-OXA $)_{\boldsymbol{n}}$ are bigger than those of the analogous derivatives with longer alkyl spacers, and therefore a decrease in conductivity is expected.

Oxadiazole type also exerts a significant influence in the conductivity values. Indeed, $\boldsymbol{b}$-PEI-(1,3,4-OXA $\left.\mathbf{A}_{\mathbf{1 0}}\right)_{\boldsymbol{n}}$ ionic polymer (green data in Fig. 6), exhibited larger conductivity values at any temperature compared to $\boldsymbol{b}$-PEI-(1,2,4-OXA $\left.\mathbf{A}_{\mathbf{1 0}}\right)_{\boldsymbol{n}}$ (light blue data in Fig. 6). For instance, the proton conductivity value for $\boldsymbol{b}$-PEI$\left(\mathbf{1}, 3,4-\mathbf{O X A}_{10}\right)_{n}$ at $100{ }^{\circ} \mathrm{C}\left(4 \times 10^{-7} \mathrm{~S} \mathrm{~cm}^{-1}\right)$ was 20 times higher than that of $\boldsymbol{b}$-PEI-(1,2,4-OXA $\left.\mathbf{1 0}_{\mathbf{1 0}}\right)_{\boldsymbol{n}}\left(2 \times 10^{-8} \mathrm{~S} \mathrm{~cm}^{-1}\right)$. This result indicates that the 1,3,4-oxadiazole isomer allows for more effective intermolecular interactions, thereby favoring a more ordered supramolecular arrangement that may enhance the proton transport by reducing the hopping distances.

On the other hand, the dendritic polymer core greatly influences the ionic conductivity. Namely, $\boldsymbol{l}$-PEI-(1,3,4-OXA $)_{n}$ side-chain polymer exhibited the lowest proton conductivity at

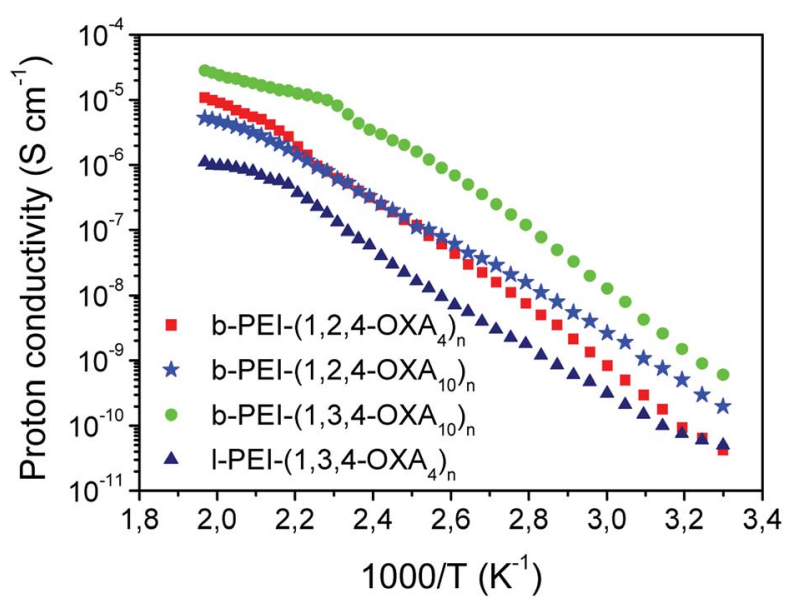

Fig. 6 Proton conductivities as a function of the temperature. 
any temperature. The hyperbranched PEI ( $\boldsymbol{b}$-PEI) core enables a more congested packing than its lineal analogue (l-PEI). Therefore, in the derivatives $\boldsymbol{b}$-PEI-(1,2,4-OXA $)_{n}, \boldsymbol{b}$-PEI-(1,2,4OXA $\left._{10}\right)_{n}, \boldsymbol{b}$-PEI-(1,3,4-OXA $\mathbf{1 0}_{n}$, the mobility of the ionic pairs is

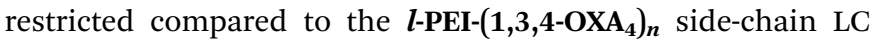
polymer, which favors their supramolecular alignment and hence contributes to enhance proton conductivities.

Because protons have to travel between electrodes, in liquid crystalline materials the measured proton conductivity depends on the macroscopic alignment of the phase with respect to the electrodes. Therefore, several alignment procedures (shearing and thermal treatments) were carried out in an effort to uniform planar alignment of the smectic layers. However, these attempts were not successful, and all measurements were performed on polydomain samples. Thus, the measured values can be considered as a lower estimation of the proton conductivity. Nonetheless, despite the fact that the conductivity values obtained for the hyperbranched ionic polymers are 3-4 orders of magnitude lower than those of obtained for non-mesogenic polymers (e.g. Nafion, poly(ethylene oxide), or poly(sulfonic) polymers), ${ }^{30,31}$ they are still high compared to other liquid crystalline materials, ${ }^{10,11,32}$ providing an attractive strategy to prepare proton conductors.

\section{Conclusions}

We have prepared new ionic LC dendrimers by complexation between a hyperbranched or linear PEI polymer and oxadiazolecontaining acids. The non-covalent architectures were obtained by the formation of the ionic salts between the carboxylic acid group and the terminal amine groups of the PEI polymers. All the compounds exhibited smectic A mesogenic behavior and linear polymers also presented a nematic mesophase. Electrochemical impedance spectroscopy measurements revealed that the LC phases obtained in these ionic hyperbranched dendrimers clearly favored proton conduction due to the presence of ionic continuous nanosegregated areas.

Our results suggest that these ionic LC dendritic polymers provide a simple and versatile strategy for the development of proton-conductive materials with potential applications in electrochemical devices.

\section{Conflicts of interest}

There are no conflicts to declare.

\section{Acknowledgements}

This work was supported by the MINECO-FEDER funds (project CTQ2015-70174), Gobierno de Aragón-FSE (Research Group E47_17R). The authors acknowledge the use of the SAI (UZ) and CEQMA (UZ-CSIC) Services.

\section{References}

1 K. Goossens, K. Lava, C. W. Bielawski and K. Binnemans, Chem. Rev., 2016, 116, 4643-4807.
2 M. Mansueto and S. Laschat, in Handbook of Liquid Crystals, ed. J. W. Goodby, P. J. Collings, T. Kato, C. Tschierske, H. Gleeson and P. Raynes, Wiley-VCH Verlag $\mathrm{GmbH} \& \mathrm{Co}$. KGaA, 2nd edn, 2014, ch. 8, vol. 6, pp. 231-280.

3 T. Kato, J. Uchida, T. Ichikawa and T. Sakamoto, Angew. Chem., Int. Ed., 2018, 57, 4355-4371.

4 V. Iguarbe, A. Concellón, R. Termine, A. Golemme, J. Barberá and J. L. Serrano, ACS Macro Lett., 2018, 7, 1138-1143.

5 T. Kato, M. Yoshio, T. Ichikawa, B. Soberats, H. Ohno and M. Funahashi, Nat. Rev. Mater., 2017, 2, 17001.

6 A. Concellón, M. Marcos, P. Romero, J. L. Serrano, R. Termine and A. Golemme, Angew. Chem., Int. Ed., 2017, 56, 1259-1263.

7 M. O'Neill and S. M. Kelly, Adv. Mater., 2011, 23, 566-584.

8 E. K. Fleischmann and R. Zentel, Angew. Chem., Int. Ed., 2013, 52, 8810-8827.

9 M. Yoshio and T. Kato, in Handbook of Liquid Crystals, ed. J. W. Goodby, P. J. Collings, T. Kato, C. Tschierske, H. Gleeson and P. Raynes, Wiley-VCH Verlag $\mathrm{GmbH} \& \mathrm{Co}$. KGaA, 2nd edn, 2014, ch. 23, vol. 8, pp. 727-749.

10 L. Vanti, S. Mohd Alauddin, D. Zaton, N. F. K. Aripin, M. Giacinti-Baschetti, C. T. Imrie, A. Ribes-Greus and A. Martinez-Felipe, Eur. Polym. J., 2018, 109, 124-132.

11 T. Liang, H. P. C. van Kuringen, D. J. Mulder, S. Tan, Y. Wu, Z. Borneman, K. Nijmeijer and A. P. H. J. Schenning, ACS Appl. Mater. Interfaces, 2017, 9, 35218-35225.

12 S. Hernández-Ainsa, M. Marcos and J. L. Serrano, in Handbook of Liquid Crystals, ed. J. W. Goodby, P. J. Collings, T. Kato, C. Tschierske, H. Gleeson and P. Raynes, Wiley-VCH Verlag GmbH \& Co. KGaA, 2nd edn, 2014, ch. 7, vol. 7, pp. 259-300.

13 P.-J. Yang, C.-W. Wu, D. Sahu and H.-C. Lin, Macromolecules, 2008, 41, 9692-9703.

14 N. Canilho, E. Kasëmi, A. D. Schlüter and R. Mezzenga, Macromolecules, 2007, 40, 2822-2830.

15 Y. Chen, Z. Shen, L. Gehringer, H. Frey and S.-E. Stiriba, Macromol. Rapid Commun., 2006, 27, 69-75.

16 A. G. Cook, U. Baumeister and C. Tschierske, J. Mater. Chem., 2005, 15, 1708-1721.

17 D. Tsiourvas, T. Felekis, Z. Sideratou and C. M. Paleos, Liq. Cryst., 2004, 31, 739-744.

18 A. F. Thünemann and J. Beyermann, Macromolecules, 2000, 33, 6878-6885.

19 R. Martín-Rapún, M. Marcos, A. Omenat, J. Barberá, P. Romero and J. L. Serrano, J. Am. Chem. Soc., 2005, 127, 7397-7403.

20 S. Hernández-Ainsa, J. Barberá, M. Marcos and J. L. Serrano, Chem. Mater., 2010, 22, 4762-4768.

21 S. Hernández-Ainsa, M. Marcos, J. Barberá and J. L. Serrano, Angew. Chem., Int. Ed., 2010, 49, 1990-1994.

22 M. Marcos, R. Martín-Rapún, A. Omenat and J. L. Serrano, Chem. Soc. Rev., 2007, 36, 1889-1901.

23 M. Marcos, R. Alcalá, J. Barberá, P. Romero, C. Sánchez and J. L. Serrano, Chem. Mater., 2008, 20, 5209-5217.

24 S. Hernández-Ainsa, J. Barberá, M. Marcos and J. L. Serrano, Macromolecules, 2012, 45, 1006-1015. 
25 S. Castelar, P. Romero, J. L. Serrano, J. Barberá and M. Marcos, RSC Adv., 2015, 5, 65932-65941.

26 A. Concellón, T. Liang, A. P. H. J. Schenning, J. L. Serrano, P. Romero and M. Marcos, J. Mater. Chem. C, 2018, 6, 1000-1007.

27 A. M. Caminade, D. Yan and D. K. Smith, Chem. Soc. Rev., 2015, 44, 3870-3873.

28 P. Davidson, A. M. Levelut, M. F. Achard and F. Hardouin, Liq. Cryst., 1989, 4, 561-571.
29 J. Barberá, L. Giorgini, F. Paris, E. Salatelli, R. M. Tejedor and L. Angiolini, Chem.-Eur. J., 2008, 14, 11209-11221.

30 K. A. Mauritz and R. B. Moore, Chem. Rev., 2004, 104, 45354586.

31 A. C. Luntz and B. D. McCloskey, Chem. Rev., 2014, 114, 11721-11750.

32 D.-J. Mulder, T. Liang, Y. Xu, J. ter Schiphorst, L. M. W. Scheres, B. M. Oosterlaken, Z. Borneman, K. Nijmeijer and A. P. H. J. Schenning, J. Mater. Chem. C, 2018, 6, 5018-5024. 